doi:10. $18575 / \mathrm{msrs} . \mathrm{sm} . \mathrm{s.1} 16.04$

UDK: 612.822

COBISS.RS-ID: 5701912

\title{
Asimetrija zadnjeg parijetalnog korteksa čovjeka: ekstrasulkusna morfometrija i višedimenzionalna analiza
}

\section{SAŽETAK}

Uvod: Istraživali smo morfometrijsku asimetriju ekstrasulkusne površine zadnjeg parijetalnog korteksa čovjeka (koru precuneusa-PEC i gornjeg parijetalnog režnjića - lobulus paarietalis superior- LPS).

Cilj rada: Ispitati moguće asimetrije ekstrasulkusne površine PPC čovjeka (PEC i LPS), primjenom višeskalarne analize: površine, kortikalne debljine i volumenske gustoće neurona PPC korištenjem naših predhodnih morfometrijskih podataka .

Materijal i metode: Na 20 mozgova (40 hemisfera) odraslih osoba mjerili smo dužinu hemisfera i ekstrasulkusnu površinu kore PEC i LPS. Zbir vrijednosti dužine hemisfera sa zbirom površina kore PEC i LPS izrazili smo kao ukupni numerički skor za razlikovanje potencijalno veće lijeve ili desne hemisfere velikog mozga čovjeka.

Rezultati: Petnaest mozgova sa većim lijevim hemisferama imali su prosjek extrasulkusne površine kore LPS: lijevo $15.04 \mathrm{~cm}^{2}$; desno $16.51 \mathrm{~cm}^{2}$; PEC: lijevo 12.9 $\mathrm{cm}^{2}$; desno $10.15 \mathrm{~cm}^{2}$. Prosječna dužina hemisfera ovih mozgova je na lijevim hemisferama $17.23 \mathrm{~cm}$, a na desnim hemisferama $16.74 \mathrm{~cm}$. Ukupni numerički skor za lijeve hemisfere bio je 45.17, a za desne hemisfere 43.40. Kod pet mozgova sa većim desnim hemisferama prosjeci ekstrasulkusne površine LPS bili su: lijevo $15.47 \mathrm{~cm}^{2}$; desno $17.24 \mathrm{~cm}^{2}$; PEC: lijevo $12.02 \mathrm{~cm}^{2}$; desno $12.2 \mathrm{~cm}^{2}$. Kod mozgova sa većim desnim hemisferama prosječna dužina desnih hemisfera bila je $17,4 \mathrm{~cm}$, a prosječna dužina lijevi hemisfera $16.9 \mathrm{~cm}$. U ovoj grupi ukupni numerički skor za desne hemisfere bio je 46.84, a za lijeve hemisfere 44.39 .

Zaključak: Dobijeni morfometrijski parametri jasno razlikuju dvije grupe mozgova, većina (petnaest) sa većom lijevom hemisferom, i manju grupu (pet) sa većom desnom hemisferom. Također, naši podaci ukazuju na to da desni precuneus čovjeka treba dalje pažljivo istraživati multiskalarnim pristupom.

Ključne riječi: ljudski mozak, morfometrija, asimetrija, precuneus, lobulus parietalis superior

(Scr Med 2016:47:21-26)

\section{Goran Spasojević," Nataša Macut Đukić, ${ }^{\text {? }}$ Slobodan Malobabicis}

${ }^{1}$ Zavod za anatomiju, Medicinski fakultet,Univerzitet Banja Luka, Republika Srpska, BiH ${ }^{2}$ Katedra za anatomiju, Medicinskifakultet Kosovska Mitrovica (Priština), Srbija ${ }^{3}$ Institut za anatomiju „Dr Niko Miljanić", Medicinskifakultet, Beograd, Srbija

\section{Kontakt adresa:}

Goran Spasojević

Medicinski fakultet Banja Luka Save Mrkalja 14, 780oo Banja Luka Republika Srpska,BiH e-mail:goraspas@yahoo.com Telefon +38751234101

Rad primljen:11.11.2015. Rad prihvaćen: 21.12.2015. 


\section{Uvod}

Zadnja parijetalna regija mozgova naših skorijih predaka je u protekla dva miliona godina naročito porasla, uz njeпu glavnu ulogu tokom evolucije ljudskog mozga, ali su osnovne funkcije zadnje parijetalne kore (posterior parietal cortex-PPC) nepromijenjene od glodara do čovjeka. ${ }^{1}$ Specijalizacije vidnog sistema obuhvatile su nova vidna podruça koja doprinose dorzalnom, "akcionom" protoku impulsa vizuomotorne obrade od ranih vidnih polja do jako uvećanog regiona PPC, koji ključno kontroliše djelovanje u realnom vгеmenu. ${ }^{2}$

Tokon evolucije pojavila se i specijalizacija dvije hemisfere za funkcije govora, jezika i druge impresivne kognitivne sposobnosti. Generalno, lijeva hemisfera većine osoba je odgoworna ( «dominantna») za verbalne, lingvističke i analitičke funkcije, čitanje i pisanje, desnorukost, racionalno i logično razmišljanje. ${ }^{3}$ Ona je kod 90-95\% dešnjaka obično dominantna za govor,ali bez odnosa sa "rukošćc»»osobe. 4 Desna («ne-dominantna») hemisfera je odgovorna za vizuospacijalne sposobnosti,emocionalno ponašanje, muzičke funkcije, procese pažnje, razumijevanje afektivnih (neverbalnih) komponenti govora i izraza lica. ${ }^{5}$ Ističeno da je problem asimetrije čovjekowog mozga za govor i jezik mnogo kompleksniji nego što se obično saopšstava pošto sugenetski efekti različiti na simetričnim i asimetričnim strukturama mozgá, budući da na dominantnost ruke značajno utičı i regionalne asimetrije asocijacione parijetalne i dorzome dijal ne frontalne kore. ${ }^{7}$ Dominantnost desne hemisfere raste linearno sa stepenom «rukosti», od $4 \%$ (izraziti dešnjaci), $15 \%$ (ambideksteri), do 27\% (izraženo ljevoruki), pri čemu sı žene češće «nekonzistentni dešnjaci». ${ }^{\mathrm{B}}$

Zadnji parijetalni korteks (PPC) obuhvata dijelove isteregije (Brodmannova area - BA7), koja čini najveći dio parijetalnog režnja, ali sadrži i BA5, ${ }^{9}$ a to su precuneus (PEC) medijalne površine i gornji parijetalni režnjić (SPL) па dorzolateral noj površini. Medjutim, PEC, kao medijalnidio $\mathrm{BA}^{7}$, nisu svi autori jasno definisali kao dio PPC. ${ }^{10}$

Brojna istraživanja morfoloških i funkcionalnih asimetrija mozga ${ }^{11}$ rijetko su obuhvatala PPC. Tako je, nakon detaljne parcelacije SPL, nekoliko njegowih područja pokazalo značajno višu varijabilnost u lijevoj hemisferi i/ili kod muskih, a samo nekoliko je imalo interakciju hemisfera i pola. ${ }^{11}$

Savremene imidžing metode (funkcionalna MRI, difuziona tenzorska traktografija, sofisticirani softveri) otvorile su nove pristupe istraživanju mozga, uključujući precizпu parcelaciju kore. ${ }^{12}$ Tako koncept difolt režima mreže (Default Mode Network- DMN) mozga, čije su komponente aktivnije u mirovanju nego tokon izwođenja za- dataka, ${ }^{12}$ traži nova tumačenja starił podataka. Svi posteriorni medijalni klasteri su uvezani u DMNN $^{13}$ i tokom mirovanja postoji jaka funkcionalna povezanost između PEC, zadnje cingularne, medijalne prefrontalne, lateralne parijetalne kore i hipokampusne formacije. ${ }^{14}$ Međutim, funkcionalna povezanost i zapremina sive mase unutar DMN nisu jednako raspoređeni medu hemisferama i funkcionalna asimetrija ne odražava uvijek strıkturne asimetrije. ${ }^{14}$

Ranije smo objavili rezultate istraživanja ljudskog PPC na makroskopskom(powršina), srednjem (kortikalna debljina) i mikroskopskon nivou (volumenska gustoća neurona). Iako ukrštanje podataka iz mikro i makro-studija može biti korisno, ovakav pristup do sada nije primjenjivan. Na primjer, na makro-skali, potiljačna kora može se opisati kao specijalizovana za vidnu obradu, na finijoj skali mogu se razlikovati različite potiljačne oblasti, a na još finijoj skali se mogu unutar potiljačnog područja razdvojiti različite vidne subregije. ${ }^{15}$

\section{Cilj rada}

Ispitati asimetrije ekstrasulkusne površine PPC čovjeka (PEC i SPL) uz dodatnu višeskalarnu analizu powršine, debljine kore i volumenske gustoće neurona, koristenjem naših prethodnih morfometrijskihı podataka.

\section{Materijal i metode}

Istraživanje ekstrasulkusne (vidljive) powršine PEC i SPL je obuhvatilo 20 mozgova ( 40 hemisfera) odraslih osoba (27-65 godina, bez vidljivih patoloskih promje na ili podataka o neuropsihijatrijskim poremécajima), u skladu sa principima Helsinške deklaracije. Nakon vađenja, mozgovi su perfundovani fizioloskom otopinom, a zatim $10 \%$ otopinom formalina, fiksirani su četiri nedjelje lebdećom fiksacijon u istom rastvoru.

Nakon pažljivog uklanjanja moždanih ovojnica i krvnih sudova prvo smo mjerili dužinu hemisfera, a poton ekstra sulkusnu površinu kore PEC i SPL, kao parametre određivanja veličine hemisfera, da bi razlikovali mozgove sa većim lijevim ili desnim hemisferama. Dužna hemisfera (fronto-okcipitalnorastojanje-FO) je pravolinijsko rastojanje (paralelnosa interkomisuralnom linijom) izmedu najistaknutijih tačaka frontalnih i okcipitalnih režnjeva. Samo ako je zbir svih tih parametara (FO + zbir površina PECi SPL), kao ukupan numerički skor, bio veći u jednoj hemisferi,tu hemisferu smo definisali kao veću. Na ovaj način smo za istraživanje odvojili petnaest mozgova sa većom lijevom hemisferom i drugih pet mozgowa sa većom desnom hemisferom. 
Slika 1. A. Precunes; B. Lobulus parietalis superior; (linije označavaju granice)
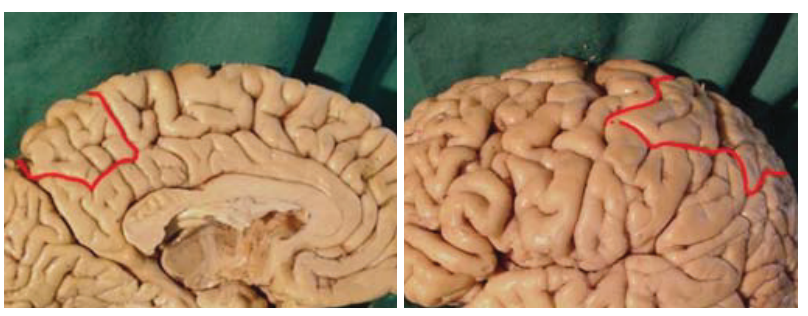

Morfometriju ekstrasulkusne površine PEC vršili smo preklapanjem jednom providnom folijom u mediosagitalnoj ravni, a mјегепja konveksne ekstrasulkusne površine SPL preklapanjem sa nekoliko providnih listova ${ }^{14}$ konačnim mjerenjem na milimetarskom papiru. U stati- stičkoj analizi koristili sno metode deskriptivne statistike i parametarski T-test.

Podaci za ponovnu analizu potičı i iz našiłh ranijih makroskopskih istražvanja (površine PEC) ${ }^{15}$, mjerenja na srednjem uveličanju (kortikalna debljina PEC i SPL) ${ }^{13}$ i mikroskopske (stereolołke) studije volumenske gustoće пешгопa petog sloja PEC i SPL. ${ }^{14}$

\section{Rezultati}

Rezultati mjerenja ekstrasulskusnih povrsina SPL i PEC mozgova s većim lijevim hemisferama prikazani su na Tabeli 1. i mozgova sa većin desnim hemisferama na Tabeli 2. Razlike između vrijednosti lijevog i desnog FO nisu bile statistički značajne ( $\mathrm{p}>0,05)$ u obje grupe mozgova.

Tabela 1. Mozgovi sa većim lijevim hemisferama $(n=15)$

\begin{tabular}{|c|c|c|c|c|}
\hline & lijevi LPS & desni LPS & lijevi PEC & desni PEC \\
\hline$X$ & $15.04 \mathrm{~cm}^{2}$ & $16.51 \mathrm{~cm}^{2}$ & $12.9 \mathrm{~cm}^{2}$ & $10.15 \mathrm{~cm}^{2}$ \\
\hline Min. & $11.69 \mathrm{~cm}^{2}$ & $11.41 \mathrm{~cm}^{2}$ & $8.31 \mathrm{~cm}^{2}$ & $9.08 \mathrm{~cm}^{2}$ \\
\hline Max. & $19.47 \mathrm{~cm}^{2}$ & $20.41 \mathrm{~cm}^{2}$ & $16.9 \mathrm{~cm}^{2}$ & $14.71 \mathrm{~cm}^{2}$ \\
\hline CV & $15.2 \%$ & $17.2 \%$ & $14.7 \%$ & $16.8 \%$ \\
\hline
\end{tabular}

$\mathrm{SPL}=$ Lobulus parietalis superior; $\mathrm{PEC}=$ precuneus

Tabela 2. Mozgovi sa većim desnim hemisferama $(n=5)$

\begin{tabular}{|c|c|c|c|c|}
\hline & lijevi LPS & desni LPS & lijevi PEC & desni PEC \\
\hline$X$ & $15.47 \mathrm{~cm}^{2}$ & $17.24 \mathrm{~cm}^{2}$ & $12.02 \mathrm{~cm}^{2}$ & $12.2 \mathrm{~cm}^{2}$ \\
\hline Min. & $11.19 \mathrm{~cm}^{2}$ & $11.41 \mathrm{~cm}^{2}$ & $10.19 \mathrm{~cm}^{2}$ & $9.45 \mathrm{~cm}^{2}$ \\
\hline Max. & $19.3 \mathrm{~cm}^{2}$ & $20.82 \mathrm{~cm}^{2}$ & $15.26 \mathrm{~cm}^{2}$ & $13.75 \mathrm{~cm}^{2}$ \\
\hline CV & $14.16 \%$ & $16.5 \%$ & $14.16 \%$ & $14.59 \%$ \\
\hline
\end{tabular}

$\mathrm{SPL}=$ Lobulus parietalis superior; $\mathrm{PEC}=$ precuneus

Mozgovi s većom lijevon hemisferom imali su ukupan numerički skor za lijevı hemisferu 45.17, a za desnu hemisferı je bio manji - 43-40. Homogenost uzorka potvrđuju mali koeficijenti varijacije (CV) za obje strane (ispod 20\%).

U grupi od ostalih pet mozgova sa većin desnim hemisferama ukupan numerički skor desnih hemisfera je 46.84 , a lijevih 44-39. Oba CV bili su praktično isti i vrlo niski.

\section{Diskusija}

Fronto-okcipitalnorastojanje(FO), upotrebljeno kao jedna od komponenti ukupnog numeričkog skora u odredivanju veće hemisfere, koristi se za indirektmu procjenu veličine mozga $\mathbf{i}$ u arheološkim istragama ostataka lobanja. ${ }^{16}$ Naš nalaz većih lijevih vrijednosti FO u grupi od 15 mozgova (lijevo FO $17.23 \mathrm{~cm}$; desno FO $16.74 \mathrm{~cm}$ ) je u skladu sa nalazima nešto veće lijeve hemisfere u opšsoj populaciji u različitih rasa i naroda ${ }^{15}$ i može se odnositi na češćı dominantnost lijeve hemisfere (više dešnjaka), kao i na lokalizaciju govornih centara u lijevoj hemisferi." Problem razlike veličine hemisfera je složen, jer je kod bijelaca lijeva hemisfera duža u $58.3 \%$, desna u $30,5 \%$ (našli smo 25\%) i obje hemisfere imaju jednake dužine u 11.2\%. ${ }^{14}$ Kako razlike između lijevih i desnih vrijednosti FO nisu bile značajne u obe skupine mozgova, weli sno dodatni, površinski parametar (zbir ekstra sulkusnih površina PEC i SPL). Adekvatnost ove druge komponente našeg ukupnog numeričkog skora potvrđuju i nalazi daje glavna kovarijansa oblika mozga usko povezana sa relativnim proporcijama $\mathrm{PEC}$, i da su uzdužne proporcije PEC glavni elementi varijabilnosti mozga u sagitalnoj ravni. ${ }^{17}$ Iako u našoj obdukcionoj studiji nismo imali podatke o dominantnosti hemisfera, detaljna analiza svih podataka iz literature, uključujući i dostupne morfološke studije, podržava korištenje ukupnog numeričkog skoraza određivanje vece hemisfere kao dominantne. 
U našoj digitalno morfometrijskoj studiji (50 mozgova) ${ }^{15}$, vrijednosti ekstra sulkusne powrsine kore PEC kod muškaraca $i$ kod žena u cjelini odgovaraju našim nalazima samo zadesni PEC mozgova sa većon desnom hemisferon. Visoko značajna razlika powršina desnog PEC muškaraca $\mathrm{i}$ žen ${ }^{16} \mathrm{i}$ veće smanjenje desnog PEC sa starošću kod muškaraca ${ }^{17}$ takođe ukazuju na desni PEC. Kod mozgova sa većin desnim hemisferama numerička gustoća neurona (Nv) petog sloja desnog PEC bila je značajno veća nego lijevog PEC. ${ }^{18}$ Kod nozgova sa većim lijevim hemisferama nas̆ nalaz najmanjeg desnog PEC je u inverznon odnosu sa nalazon izuzetno deblje kore desnog PEC, što nije slučaj kod mozgowa sa većim desnim hemisferama. ${ }^{13}$

Naši sadašnji i prethodni podaci nedvosmisleno potvrđuju značajne razlike između grupa mozgova sa većim lijevim i desnim hemisferama, sa posebnim osvrtom na parametre desnog PEC. ${ }^{13,15}$ U prilog owome govore značajne desno-lijeve asimetrije medijalne površine zadnjił regija, nesignifikantno veća površina desnog PEC, deblja kora lijevog PEC muškaraca uz odsustvo korelacije površine i debljine kore PEC. ${ }^{17}$ PPC ina ključnu ulogu u brzon donošenju odluka, senzornoj pažnji, motornim namjerama i/ili radnoj memoriji. ${ }^{3}$ Vidno-prostorne sposobnosti prvenstveno posreduje desna hemisfera i upravo desni PPC neposrednim transkalozalnim projekcijama jako inhibira aktivnost suprotnog. ${ }^{3}$ Svi klasteri posteriorno-medijalne kore su usko povezanisa DMN. ${ }^{17}$ Dok neki autori isključuju PEC iz DMN, drugi tvrde daje PEC glavni čvor DMN ljudskog mozga. ${ }^{18}$

Prekunealni klaster (povezan s pažnjom i motoričkih zadacima) je uglavnom povezani sa desnim slepoočno-parijetalnim spojem. ${ }^{17,18}$ Mnoge od unutrašnjih funkcionalnih moždanih mreža su jako lateralizowane, pri čemu je DMN pretežno lijevo lateralizovan. Vizuelna mreža je snažno desno lateralizovana ${ }^{4}$, što opet ukazuje na desni PEC. Za razliku od desnog PEC, našli sno da je desni SPL bio veći u obe grupe mozgova.

SPLje senzomotorni "interfejs" za vidon vođene pokrete ${ }^{5}$, a bilateralne gornje parijetalne regije direktno su povezane sa varijabilnošćc stope percepcije $\mathrm{e}^{6}$ starenjen se više smanjuju kod muškaraca. ${ }^{9}$ Znatno veće vrijednosti kortikalne debljine i Nv u lijevim SPL mozgova sa većin lijevim hemisferama ${ }^{5}$ odgovaraju lijevo-desnoj asimetriji debljine kore SPL. ${ }^{9}$ Lijevi SPL, koji je prilikom prisjećanja aktivniji kod draži pravilno identifikovanih kao "stare" u odnosu na "nove,"7 imao je najveći Nv među ispitivanim regijama (PEC i SPL) u obje grupe mozgova. ${ }^{4}$

Naziv "asocijacioni korteks" ne opisuje jedinstven entitet budući da stepen specijalizacije znatno varira između različitih područja asocijacione kore, jer kompleksne zone parijetalnih regija mogu biti od vrlo specijaliziranih do vrlo fleksibilnih, a SPL spada u fleksibilne regije. ${ }^{18}$

Zbog složenosti i nedostatka vremena za MRI mjerenja uveli smo novi kombinovani parametar, ukupan numerički skor (FO + zbir PEC i LPS), za određivanje većih hemisfera na pojedinačnim mozgovina. Očigledno je da mjerenja samo jednog, pa i više kortikalnih parametara, nisu dowoljna da daju tačne podatke o asimetrijama ljudskog mozga. Naš višedimenzionalan pristup opravdava i tvrdnja da se funkcionalne specijalizacije mogu pripisati različitim prostornim skalama. ${ }^{11}$ Zoog našeg nalaza da je grupa mozgova sa većim desnim hemisferama proporcionalno veća od broja ljevorukih, pretpostavljamo da su neki od tih mozgova poticali od dešnjaka. Stoga očekujemo da neke od predodređenih funkcija desne hemisfere mogu biti izraženije nego obično u mozgovima sa većim desnim hemisferama, s̆to zashužuje daljnje in-vivo studije.

\section{Zaključak}

Naši rezultati ukazuju da proučavanje morfološke asimetrije mozga mora uključiti podatke o veličini mozga, cerebralnoj dominaciji, dobu, spolu ispitiva nił osoba i treba ga istovremeno vršiti u različitim, odabranim dimenzijama, odnosno više dimenzionalnom analizon.

\section{Reference}

1. Kaas HJ. The Evolution of Brains from Early Mammals to Humans. Wiley Interdiscip Rev Cogn Sci. 2013: 4: 33-45.

http//dx.doi.org/10.1002/weg. 1206

PMid:23529256 PMCid:PMC3606080

2. Brumer E. Geometric morphometries and paleoneurology: brain shape evolution in the genus Homo. J Human Evol 2004: 47279-303-

http//dx.doi.org/10.1016/j.jhevol.2004.03.009

3. Broussard J. Posterior parietal cortex dynamically ranks topographic signals via cholinergic influence. Front Integr Neurosci $2012 ; 6: 32$.

http//dx.doi.org/10.3389/fnint.201200032

4. Goodale AM. How (and why) the visual control of action differs from visual perception. Proc R Soc 2014: B 281: 20140337.

http//dx.doi.org/10.1098/rspb.2014.0337

5. Heilman KM, Bowers D, Valenstein E, Watson RT. The right hemisphere: neuropsychological functions. J Neurosurg 1986; $64: 693-704$.

http://dx.doi.org/ 10.3171/jns.1986.64.5.0693

PMid:3517248

6. Penfield W, Roberts L. Speech and Brain Mechanisms. Princeton: Princeton University Press, 1969. PMid:4902635 
7. Wright IC, Sham P, Murray RM, Weinberger DR, Bullmore ET. Genetic. Contributions to Regional Variability in Human Brain Structure: Methods and Preliminary Results. NeuroImage $2002 ; 17: 256-271$

http//dx.doi.org/10.1006/nimg.2002.1163

PMid:12482082

8. Hamilton LS, Narr KL, Luderg E, Szeszko PR, Thompson PM,. Bilder RM, Toga AW. Asymmetries of cortical thickness: effects of handedness, sex, and schizophrenia. Neuroreport 2007; 18: 1427-1431. doi:10.1097/WNRobo13e3282e9a5a2

http//dx.doi.org/10.1097/WNR.obot3e3282e9a5a2

9. Knecht S, Drager B, Deppe M, Biobe L, Lohman H, Floel A, Ringelstein E-B, Heningsen $H$. Handedness and hemispheric language dominance in healthy humans. Brain $2000 ; 123:$ $2512-2518$.

http///dx.doi.org/10.1093/brain/123.12.25.12

PMid:11099452

10. Witelson SF. Brain asymmetry, functional aspects. In: Adelman G, editor. Encyclopedia of Neuroscience. Boston: Birkhauser, $1987: 152-156$. Creutzfeldt OD. Cortex cerebri. Berlin: Springer-Verlag; 1983 .

\section{PMid:2886296}

11. Witelson SF, Kigar DL. Asymmetry in brain function follows asymmetry in anatomical form: gross, microscopic, postmortem and imaging studies. In: Boller F, Grafman J, editors. Handbook of Neuropsychology. Amsterdam: Elsevier Science, 1988: $111-142$.

12. Creutzfeldt OD. Cortex Cerebri. Berlin: Springer-Verlag; 1983 httpl//dx.doi.org/10.1007/978-3-642-68962-8

\section{PMCId:PMC1197302}

13. Djukić Macut N, Malobabić S, Spasojerić G. Asymmetry and various thickness of the human posterior parietal cortex. Scripta Med 2009; 40: 1-8.
14. Scheperjans F, Eick hoff SB, Hoemke L, Mohlberg H, Hermann $\mathrm{K}$, Amunts $\mathrm{K}$, et al. Probabilistic maps, morphometry, and variability of cytoarchitectonic areas in the human superior parietal cortex. Cereb Cortex 2008; $18: 2141-57$.

http://dx.doi.org/10.1093/cercor/bhm116

http://dx.doi.org/10.1093/cercor/bhm241

PMid:18245042 PMCid:PMC3140197

I5. Spasojević G, Malobabić S, Šuščević D, Miljłović Ž. Morphometric variability of precumeus in relation to gender and to hemisphere of human brain. Vojnosanit Pregled 2004; 61: 365370 . $\mathrm{http} / / \mathrm{dx} . \mathrm{doi}$ org/10.2298/VSPO404365S

16. Nelson SW, Cohen AL, Power JD, Wig GS, Miezin FW, Wheeler ME, et al. A parcellation scheme for human left lateral parietal cortex. Neuron 2010;67:156-70.

http//dx.doi.org/10.1016/j.neuron.2010.05.025

PWid:20624599 PMCid:PWC2913443

17. Crespo-Facorro B, Kim J-J, Andreasen NCU, Spinks R, O'Leary DS, Bockholt JH, Harris G. Magnotta VA. Cerebral cortex: a topographic segmentation method using magnetic resonance imaging. Psychiatry Research: Neuroimaging Section 2000; 100: $97^{-126 .}$

http//dx.doi.org/10.1016/So925-4927/60)00072-X

18. Raichle ME, Snyder AZ. A default mode of brain function: a brief history of an evolving idea. Neuroimage $2007 ; 37: 1083-1090$. doi: 10.1016/j.neuroimage.2007.02.041

http//dx.doi.org/10.1016/j.neuroimage.2007.02.041Asymmetry of the Human Posterior Parietal Cortex:Extrasulcal Morphometry and Multidimensional Analysis 


\section{Asymmetry of the Human Posterior Parietal Cortex: Extrasulcal Morphometry and Multidimensional Analysis}

\section{ABSTRACT}

Introduction. We researched the morphometric asymmetry of the extrasulcal surfaces of the human posterior parietal cortex (precuneus-PECand superior parietal lobule-SPL).

Aim of the study. Our aim was to examine potential asymmetries of the extrasulcal surfaces of the PEC and SPL with multiscalar analysis of surface, cortical thickness and neuronal volume densities using our previous morphometric data.

Material and methods. On 20 brains (40 hemispheres) of adults we measured the length of the hemispheres and extrasulcal surfaces of the PEC and SPL. The sum of value of hemispheric length and the sum of PEC and SPL extrasulcal surfaces obtained total numerical scores for potential distinct differentiation of brains with larger left or right hemispheres.

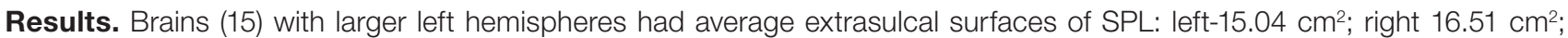
of PEC: left12.9 $\mathrm{cm}^{2}$; right $10.15 \mathrm{~cm}^{2}$. The average length of the left hemispheres in these brains was $17.23 \mathrm{~cm}$, and the average length of the right hemispheres was $16.74 \mathrm{~cm}$. The total numerical score for left hemispheres was 45.17 , and for right hemispheres 43.40. In five brains with larger right hemispheres the average extrasulcal surfaces of SPL were: left 15.47cm²; right $17.24 \mathrm{~cm}^{2}$; of PEC: left $12.02 \mathrm{~cm}^{2}$; right $12.2 \mathrm{~cm}^{2}$. In the brains with larger right hemispheres the average right hemispheric length was $17.4 \mathrm{~cm}$, and the average left hemispheric length was $16.9 \mathrm{~cm}$. In this group the total numerical score for right hemispheres was 46.84, and for left hemispheres 44.39.

Conclusion. The obtained morphometric parameters clearly distinguished two groups of brains, majority (fifteen) with larger left hemispheres, and few (five) with larger right hemispheres. Also, our data indicate that human right precuneus deserves further careful studies by multiscale approaches.

Key words: human brain, morphometry, asymmetry, precuneus, superior parietal lobule. 